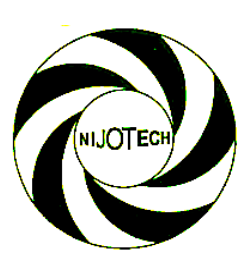

Nigerian Journal of Technology (NIJOTECH)

Vol. 37, No. 3, July 2018, pp. $\mathbf{8 5 3 - \mathbf { 8 6 0 }}$

Copyright@ Faculty of Engineering, University of Nigeria, Nsukka,

Print ISSN: 0331-8443, Electronic ISSN: 2467-8821

http://dx.doi.org/10.4314/njt.v37i3.40

\title{
A PRELIMINARY INVESTIGATION OF THE BIOMETRY OF KNEE PAIN FOR DEVELOPMENT OF THERAPEUTIC DEVICE FOR THE MANAGEMENT OF KNEE OSTEOARTHRITIS
}

\author{
0. 0. E. Ajibola1, ${ }^{1}$, 0. 0. Kareem ${ }^{2}$, D. O. Odebiyi ${ }^{3}$ and A. Aiyegbusi ${ }^{4}$ \\ 1, DEPARTMENT OF SYSTEMS ENGINEERING, UNIVERSITY OF LAGOS, AKOKA, YABA, LAGOS STATE. NIGERIA \\ 2, DEPARTMENT OF BIOMEDICAL ENGINEERING, UNIVERSITY OF LAGOS, IDI-ARABA, LAGOS STATE. NIGERIA \\ 3.4. DEPARTMENT OF PHYSIOTHERAPY, UNIVERSITY OF LAGOS, IDI-ARABA, LAGOS STATE. NIGERIA \\ Email addresses: ${ }^{1}$ waleisiro@yahoo.com; ${ }^{2}$ Ioveandfavour2014@gmail.com, 3 femiodebiyi@yahoo.com, \\ 4 aaiyegbusi@unilag.edu.ng
}

\begin{abstract}
In engineering design there is the necessity to carry out biometry of an ailment on sufferers as a pedestal for development of a device that manages the ailment. In this paper, we have carried out the biometry of pain in patients of knee osteoarthritis (OA). The study evaluates causes of knee pain, its severity and effects on daily activities, psychosocial life and sleep. The study population was drawn from five government hospitals in Lagos State. After initial treatment, only patients with knee pain were enlisted as subjects in the study. A standardized questionnaire was used for data collection to determine the causes of the pain, its severity and effects on the operational performance of individuals with $O A$. Chi-square analysis was carried out on our samples at a statistical level of significance of $\alpha=0.05$. Out of 525 questionnaires that were distributed, 431 (82.10\%) were responded to. The outcomes of this study indicate that $O A$ affects individuals of all ages and genders irrespective of their topographical locations. 242 (89.67\%) women and 189 (88.97\%) men were affected with higher incidence recorded within the age groups of (41-50) and (61-70) with frequency values of 62 (84.00\%) and 85 (92.85\%) respectively. The risk factors include overweight, occupational hazard and previous history of knee injury. Overweight 132 (91.86\%), Obesity 59 (92.28\%) and Extreme Obesity 5 (90.37\%). Previous injury 173 (90.52) \% and non-previous injury is 258 (87.78\%). This work studies biometrics of $O A$ as basis for developing a therapeutic management of knee $O A$, and this is to improve the patient's pain tolerance and relief of swollen knee without adverse effect.
\end{abstract}

Key words: knee, joint pain, osteoarthritis, therapeutic device, weight, injury

\section{INTRODUCTION}

Osteoarthritis (OA) is an inflammation of joints that is marked by degeneration of the cartilage and bones of the joints. A major cause of disability, OA is accompanied by varying levels of functional limitation. $\mathrm{OA}$ is also known as degenerative arthritis and it is the most common joint disorder that damages and destroys joints. Its high prevalence, especially in the adult, and the high rate of disability is associated with the disease make it a leading cause of disability in adults [1]. The World Health Organization (WHO) estimated that $80 \%$ of people suffering from $\mathrm{OA}$ experience some limitation in mobility, another $25 \%$ were unable to carry out important activities of daily life due to $\mathrm{OA}[2,3]$. The severe pain and dysfunction resulting from $\mathrm{OA}$ is the outcome of a destructive inflammatory process that degrades the cartilage, bone, and tissues comprising the affected joint area [4]. In most cases, $\mathrm{OA}$ is reported after the age of 40 . Due to chronic inflammation around a joint, the protective cartilage wears away, causing bone ends to rub against each other. The usual medical treatment for these conditions consists mainly of anti-inflammatory drugs, pain relief measures and physiotherapy to keep a certain degree of mobility in affected joints. The limitation of any treatment is that it can only slow down but cannot reverse the progressive deterioration of the disease. When aspirin and other pain relieving drugs are involved, the intestinal wall becomes less efficient in blocking harmful partly digested nutrients thereby worsening the symptoms in the long term [5].

* Corresponding author, tel: +234-802 - $302-5053$ 
A joint is where two or more bones meet. The joint allows the bones to move freely. These movable joints consist of the following parts: cartilage, a hard but slippery coating on the end of each bone. The cartilage breaks down and wears away by osteoarthritis. Joint capsule is a tough membrane sac which encloses all the bones and other joint parts. Synovium is a thin membrane inside the joint capsule that secretes synovial fluid. Synovial fluid lubricates the joint and keeps the cartilage smooth and healthy [6]. The knee is the largest and one of the most complicated joints in the body. It requires strength to be able to withstand the body's weight. The knee is a flexible, weightbearing joint that is prone to wear-and-tear and therefore likely to be affected by osteoarthritis [7]. In people who suffer from $\mathrm{OA}$, the cartilage breaks down, leading to an overgrowth of bone underneath. The cartilage becomes rough and then wears away: when it wears away it causes pain, swelling, and restricts the movement at the joint. The symptoms worsen over time [8]. To this end, the knees are the most affected by degenerative arthritis of all the joints. Symptoms of knee OA include stiffness, swelling, pain and by implication difficulty to walk, climb, and get in and out of chairs. Degenerative arthritis in the knees can lead to disability in the future. It can damage either one (unilateral) or both (bilateral) sides of the knee joint. It happens more mostly on the inner (medial) aspect of the knee.

There are levels/stages of increasing severity for degenerative arthritis ranging from minor to severe [8]:

Stage 0: normal knee health, the time after an injury or a physical exam or an $\mathrm{X}$-ray is taken.

Stage 1: minor, this is the stage when small lumps of bone (called osteophytes) develop in the knee region. The cartilage may be slightly damaged.

Stage 2: mild, during this stage, the symptoms of $\mathrm{OA}$ begin to become more noticeable and the patient experiences such symptoms as stiffness or joint pain.

Stage 3: moderate, during this stage, the damage to the cartilage has progressed and the patient may begin to feel pain and discomfort while performing everyday activities. Running, walking, kneeling, and bending may cause discomfort. At this stage, the feeling of inflammation becomes real. As OA progresses, the cartilage continues to thin and tears away.

Stage 4: severe, this stage is the most advanced stage of OA where the symptoms become more obvious. There is more friction in the joint and greater pain and discomfort when walking. In extreme case, the patient loses the ability to walk.

People with OA will likely grow more bone lumps and feel pain often while performing simple tasks such as walking. In severe cases, the bones may become deformed and angulated because of asymmetric loss of cartilage [2]. In a healthy knee, the presence of cartilage enables the leg bones and the patella to glide smoothly during the joint's hinge-like movements. But with knee osteoarthritis, this cartilage begins to degenerate, either due to the wear and tear of aging, previous injury, or both. The first sign of knee osteoarthritis is always pain, swelling, or stiffness in the knee, which shows that the knee's cartilage is inflamed. The inflamed knee cartilage starts to thin and may even disappear completely, causing direct friction of the knee bones against one another. This boneon-bone friction can lead to the growth of osteophytes, or bone spurs, in the knee joint, which can cause pain if they increase joint friction. As knee osteoarthritis progresses, patients can lose some or all of the knee's range of motion, or its ability to withstand the body's weight [6]. Pain is the common parameter that occurs in all levels of $\mathrm{OA}$.

The fundamental goal of therapy is to diminish the problems related with osteoarthritis. It reduces pain, decreases the trend of disability, improves the patient's physical functioning and to lessen any resulting problems. With therapy, patients with mild or even moderate symptoms can avoid the use of drug at least for a considerable length of time $[9,10]$. The primary risk factors associated with OA are advanced age (over 45 years), previous knee injury, and excess weight [3, 4]. However, the risk is greater in those who are overweight, those with different leg lengths, and those whose jobs result in high grades of joint stress. OA is believed to be caused by mechanical stress on the joint and low grade inflammatory processes [7, 9]. In addition, joint injury, a broken bone, severe trauma or surgical operation may induce pain to the knee joint that finally becomes knee $\mathrm{OA}$, although symptoms may not appear until many years after. Osteoarthritis that develops as a consequence of old injury is usually termed Traumatic Arthritis, or Post-traumatic Arthritis $[11,12]$.

Adult females are more likely to develop degenerative arthritis in the knee than males (Table 1). For adults over the historic period of $46,18.7 \%$ of women have knee osteoarthritis and $16.6 \%$ of men have knee osteoarthritis while the above risk factors predispose certain individuals to osteoarthritis, they are not absolutely causative: people without the above risk factors may develop the condition and people with all of the above features may never get it. Severe cases 
may require joint replacement surgery, particularly for knee OA [13].

Table 1: Gender analysis

\begin{tabular}{lllll}
\hline & Frequency & No pain & Pain & Total \\
\hline Male & 189 & $11.03 \%$ & $88.97 \%$ & $100.00 \%$ \\
Female & 242 & $10.33 \%$ & $89.67 \%$ & $100.00 \%$ \\
\hline
\end{tabular}

$\mathrm{OA}$ is diagnosed through a physical examination and review of symptoms, X-rays, and laboratory tests.[14]. The diagnosis of OA is typically symptomatic based, with medical imaging and other tests occasionally used to either support or rule out other problems. While osteoarthritis is a disease of the joints, its effects are not only physical. In many people with degenerative joint disease, lifestyle and finances are also affected. The lifestyle effects include: depression and anxiety, sleep disturbances, feelings of helplessness, limitations on daily activities, job limitations and difficulty participating in daily personal and family joys and duties. Financial effects are the cost of treatment and wage lost as a result of disability. The purpose of $\mathrm{OA}$ treatment is therefore to control symptoms, prevent disease progression, and improve functionality and quality of life [14-16].

Currently, there is no cure for most types of arthritis. Various therapies only manage symptoms to improve overall quality of life. This study is designed to provide a springboard for the development of a therapeutic device for improved management of pains associated with the condition. No side effects were encountered in the studies, but in general, subjects report that thermotherapy is safe when used carefully [17]. We therefore propose therapeutic device with combination of cold and heat therapies in a single device. Heat and cold are the two most common types of passive, non-invasive, and non-addictive therapies. Both methods are simple. An inexpensive and easy way to manage arthritis-related aches and pains is by applying heat or cold to the affected joints $[10,18]$. Heatcan relax muscles and help lubricate joints. Heat therapy may be used to relieve muscle and joint stiffness, help warm up joints before activity, or ease a muscle spasm. Cold can reduce inflammation, swelling, and pain related to arthritis and activity $[17,19]$.

The significance of this research is to establish some facts about Knee $\mathrm{OA}$ and to prepare a strong pedestal for development of a therapeutic device which will assist patients with knee OA to improve their sense of well-being and slows down or prevent joint damage. The significant goal of rehabilitation is to return patients to active, pain free and fully functional state.

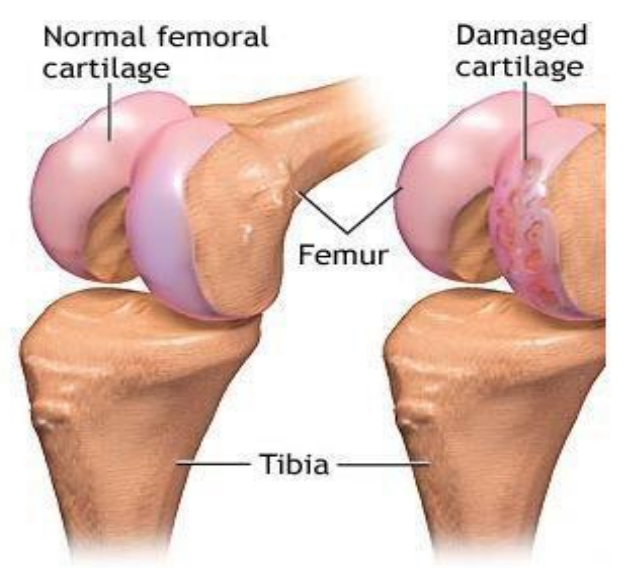



Healthy knee joint

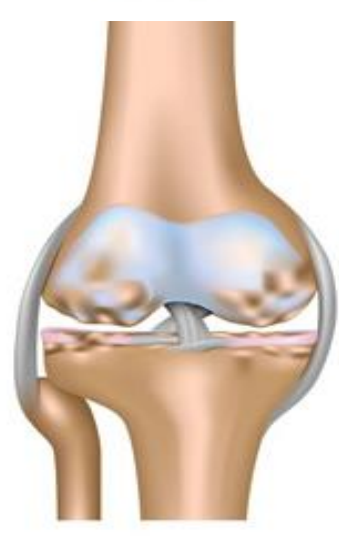

Osteoarthritis Figure 1: Description of cartilage wear

\section{MATERIALS AND METHODS}

The target research population of this study was patients with knee OA from one tertiary hospital and four secondary hospitals located in the following local governments in Lagos State: Agege local Government, Surulere Local government, Ikorodu Local government, Lagos Inland local government and Mushin Local government. The research was conducted between October-November, 2017 in the departments of Physiotherapy, Medical out-patients and Orthopedic of the following hospitals: Lagos General Hospital, Ikorodu General Hospital, Orile Agege General Hospital, Randle General Hospital, Surulere and Lagos University Teaching Hospital (LUTH). Permission was given by the Lagos State health Commission and ethical approval committee of LUTH to conduct the research in selected hospitals. A total of 525 questionnaires were administered to patients with knee pain in the pattern contained in Table 2:

These data were entered into Microsoft Excel spreadsheet and analyzed with SPSS version 17. Responses to each questionnaire item on the knee OA were recorded in the study. Other data extracted included biodata (age, sex, weight etc.), causes and 
symptoms, psychosocial, sleep disturbances and level of pain. The biodata are as summarized in Table 3:

Evaluation of pain was done on nominal scale of 0 to 10 , where 0 is no pain, 10 stands for worst pain and 5 is moderate pain. Inclusion criterion used in the study is primary diagnosis of knee OA. Patients were excluded from the study if they had a primary diagnosis other than knee OA. And the following demographics were extracted from the patients: Age (as at last birthday), Weight (kg), Height (m), Body Mass Index (BMI) $\left(\mathrm{kg} / \mathrm{m}^{2}\right)$, Sex, Previous Injury, Employment Status, Occupation, Educational Attainment Level, Current Treatment, and Affected Knee. The researcher made use of questionnaires method, interviews and observations for a better result. Since the larger percentage of the research information is made up of questionnaires circulated and questions asked through interviews, simple percentage average is used. It is noted that the research instrument employed has the basic motives: to detect the causes of knee OA, to evaluate level of knee pain and its effects on functional performance, psychosocial life and sleep on an individual with this condition. The processed copies of this research work was assessed and approved by experienced personnel. The involvement of research experts ensured that the questionnaire was structured and standardized type making it easy to answer by respondents and simple to analyze by the researcher.

Table 2: Questionnaires distribution analysis

\begin{tabular}{cccccc}
\hline & $\begin{array}{c}\text { No of Questionnaire } \\
\text { distributed }\end{array}$ & Answered & Unanswered & \% Answered & \% Unanswered \\
\hline Lagos & 100 & 79 & 21 & $79.00 \%$ & $21.00 \%$ \\
Agege & 100 & 63 & 37 & $63.00 \%$ & $37.00 \%$ \\
Ikorodu & 175 & 149 & 26 & $85.10 \%$ & $14.90 \%$ \\
Randle & 50 & 92 & 2 & $84.00 \%$ & $16.00 \%$ \\
LUTH & 100 & 431 & 94 & $98.00 \%$ & $2.00 \%$ \\
TOTAL & 525 & & & $82.10 \%$ & $17.90 \%$ \\
\hline
\end{tabular}

Table 3: Age group analysis

\begin{tabular}{lllll}
\hline Age Group & Frequency Value & No Pain (\%) & Pain (\%) & \\
\hline$<=30$ & 26 & $27.35 \%$ & $72.65 \%$ & $100.00 \%$ \\
$31-40$ & 22 & $22.03 \%$ & $77.97 \%$ & $100.00 \%$ \\
$41-50$ & 62 & $16.00 \%$ & $84.00 \%$ & $100.00 \%$ \\
$51-60$ & 123 & $10.69 \%$ & $89.31 \%$ & $100.00 \%$ \\
$61-70$ & 85 & $7.15 \%$ & $92.85 \%$ & $100.00 \%$ \\
$71-80$ & 97 & $7.29 \%$ & $92.71 \%$ & $100.00 \%$ \\
$81-90$ & 16 & $9.49 \%$ & $90.51 \%$ & $100.00 \%$ \\
\hline
\end{tabular}

Table 4: BMI analysis

\begin{tabular}{lcccc}
\hline & Frequency Value & No Pain (\%) & Pain (\%) & Total \% \\
\hline Under weight & 10 & $26.94 \%$ & $73.06 \%$ & $100.00 \%$ \\
Normal & 225 & $13.38 \%$ & $86.62 \%$ & $100.00 \%$ \\
Overweight & 132 & $8.14 \%$ & $91.86 \%$ & $100.00 \%$ \\
Obese & 59 & $7.72 \%$ & $92.28 \%$ & $100.00 \%$ \\
Extreme obese & 5 & $9.63 \%$ & $90.37 \%$ & $100.00 \%$
\end{tabular}

Table 5: History of previous injury analysis

\begin{tabular}{lllll}
\hline Have you had injury involved your knee & Frequency Value & No pain (\%) & Pain (\%) & $\%$ Total \\
\hline Yes & 173 & $9.48 \%$ & $90.52 \%$ & $100.00 \%$ \\
No & 258 & $12.22 \%$ & $87.78 \%$ & $100.00 \%$ \\
\hline
\end{tabular}

Table 6: Knee Analysis

\begin{tabular}{lllll}
\hline Knee & Frequency Value & No pain (\%) & Pain (\%) & Total \\
\hline Right & 236 & $11.91 \%$ & $88.09 \%$ & $100.00 \%$ \\
Left & 112 & $10.58 \%$ & $89.42 \%$ & $100.00 \%$ \\
Both & 83 & $9.59 \%$ & $90.41 \%$ & $100.00 \%$ \\
\hline
\end{tabular}


Table 7: Employment status Analysis

\begin{tabular}{lcccc}
\hline & Frequency value & No Pain (\%) & Pain (\%) & \% Total \\
\hline Yes & 202 & $14.30 \%$ & $85.70 \%$ & $100.00 \%$ \\
No & 61 & $12.52 \%$ & $87.48 \%$ & $100.00 \%$ \\
Retired & 168 & $9.07 \%$ & $90.93 \%$ & $100.00 \%$ \\
\hline
\end{tabular}

The data were analyzed by using simple percentages but stratification of subjects in accordance with their level of pain was based on assigned responses described below:

- To assess how the pain has affected functionality activities, psychosocial and sleep, the following nominal statistics were used: Never (1), Rarely (2), Sometimes (3), Often (4), and Always (5)

- To evaluate the intensity of the pain during daily activities, following scale were used: No Pain (1), Mild Pain (2-4), Moderate pain (5-7), Severe Pain (8-9) and Worst Pain (10).

\subsection{Statistical analysis}

The statistical tools employed in analyzing the data collected include frequency tables and simple percentages. The chi-square $\left(\chi^{2}\right)$ statistics was used to compare an actual (or observed) with a hypothesis (or expected) distribution. In testing the hypothesis 5\% level of significance was employed. Thus, 95\% level of confidence was placed on the accuracy of the results of the study translating to $5 \%$ level of risk. If $\mathrm{p}$-value < 0.05 then $\mathrm{H}_{0}$ is rejected. This implies that alternative hypothesis $\left(\mathrm{H}_{1}\right)$ will be accepted. And the four hypotheses to be tested in this study are:

- Null Hypothesis: There is no significant relationship between BMI and Knee Pain Alternative Hypothesis: There is significant relationship between BMI and Knee Pain

- Null Hypothesis: There is no significant relationship between performance and knee pain

Alternative Hypothesis: There is significant relationship between performance and knee pain
- Null Hypothesis: There is no significant influence of knee pain on psychosocial life and sleep disturbances

Alternative Hypothesis: There is significant influence of knee pain on psychosocial life and sleep disturbances

- Null Hypothesis: There is no significant influence of knee pain on functionality

Alternative Hypothesis: There is significant influence of knee pain on functionality

\section{RESULTS AND DISCUSSION}

Five hundred and twenty five (550) questionnaires were distributed and four hundred and thirty one (431) questionnaires were recovered translating to ninety four questionnaires were not returned. The data fields are: General Hospital Lagos, Odan where one hundred questionnaires were distributed and seventy nine questionnaires were answered. Orile Agege General Hospital, Agege where one hundred questionnaires were distributed and sixty three questionnaires were returned, Ikorodu General Hospital, Ikorodu with One hundred and seventy five questionnaires distributed and one hundred and forty nine questionnaires were answered. This is due to the large number of patients visiting the hospital on a daily basis. Randle General Hospital, Surulere where Fifty questionnaires were distributed and forty two questionnaires were answered. Lagos University Teaching Hospital, LUTH the tertiary health facility where one hundred questionnaires were distributed and ninety eight questionnaires were answered.

Table 8: Relationship between BMI and knee pain

\begin{tabular}{|c|c|c|c|c|c|c|c|}
\hline \multicolumn{8}{|c|}{ What level of knee pain have you experienced during picking up an object? } \\
\hline & & No & Mild & Moderate & Severe & Worst & \\
\hline & & $\begin{array}{l}\text { Pain } \\
(1)\end{array}$ & $\begin{array}{l}\text { Pain } \\
(2-4)\end{array}$ & $\begin{array}{l}\text { Pain } \\
(5-7)\end{array}$ & $\begin{array}{l}\text { Pain } \\
(8-9)\end{array}$ & $\begin{array}{l}\text { Pain } \\
(10)\end{array}$ & Total \\
\hline \multirow[t]{6}{*}{ BMI_Status } & Underweight & 2 & 7 & 1 & 0 & 0 & 10 \\
\hline & Normal Weight & 13 & 54 & 154 & 2 & 2 & 225 \\
\hline & Overweight & 1 & 29 & 102 & 0 & 0 & 132 \\
\hline & Obesity & 2 & 15 & 39 & 3 & 0 & 59 \\
\hline & Extreme Obesity & 0 & 3 & 2 & 0 & 0 & 5 \\
\hline & Total & 18 & 108 & 298 & 5 & 2 & 431 \\
\hline
\end{tabular}


A Preliminary InVestigation of the Biometry of Knee PAin For Development of TheraPeutic ... 0. 0. E. Ajibola, et. al

Table 9: $\chi 2$ Test of effect of BMI on knee pain

\begin{tabular}{|c|c|c|c|c|c|c|c|}
\hline & & \multicolumn{2}{|c|}{ Value } & df & \multicolumn{3}{|c|}{ Asymp. Sig. (2-sided) } \\
\hline \multicolumn{2}{|c|}{ Pearson Chi-Square } & \multicolumn{2}{|c|}{ 41.013(a) } & 16 & \multicolumn{3}{|c|}{0.001} \\
\hline \multicolumn{2}{|l|}{ Likelihood Ratio } & \multicolumn{2}{|c|}{38.623} & 16 & \multicolumn{3}{|c|}{0.001} \\
\hline \multicolumn{2}{|l|}{$\mathrm{N}$ of Valid Cases } & \multicolumn{2}{|c|}{431} & & & & \\
\hline \multirow{2}{*}{\multicolumn{8}{|c|}{$\begin{array}{l}\text { The } \mathrm{p} \text {-value }=0.001 \text { is less than } 0.05 \text {, therefore the null hypothesis is rejected while the alternative is accepte } \\
\text { which states there is significant relationship between BMI and knee pain. }\end{array}$}} \\
\hline & & & & & & & \\
\hline & & \multicolumn{5}{|c|}{ What level of knee pain have you experienced during standing? } & \multirow[b]{2}{*}{ Total } \\
\hline & & No Pain (1) & $\begin{array}{l}\text { Mild Pain } \\
\quad(2-4)\end{array}$ & $\begin{array}{l}\text { Moderate Pain } \\
(5-7)\end{array}$ & $\begin{array}{c}\text { Severe } \\
\text { Pain }(8-9)\end{array}$ & $\begin{array}{c}\text { Worst } \\
\text { Pain }(10)\end{array}$ & \\
\hline \multirow{6}{*}{$\begin{array}{l}\text { How often do } \\
\text { you experience } \\
\text { knee pain? }\end{array}$} & Never & 4 & 9.00 & 9 & 0 & 0 & 22 \\
\hline & Rarely & 7 & 34.00 & 60 & 7 & 1 & 109 \\
\hline & Sometimes & 2 & 56.00 & 189 & 4 & 1 & 252 \\
\hline & Often & 0 & 7.00 & 31 & 1 & 0 & 39 \\
\hline & Always & 0 & 5.00 & 4 & 0 & 0 & 9 \\
\hline & Total & 13 & 111.00 & 293 & 12 & 2 & 431 \\
\hline
\end{tabular}

Table 11: $\chi 2$ Test of performance of knee versus pain

\begin{tabular}{lccc}
\hline & Value & df & Asymp. Sig. (2-sided) \\
\hline Pearson Chi-Square & $51.556^{\mathrm{a}}$ & 16.00 & 0.00 \\
Likelihood Ratio & 44.14 & 16.00 & 0.00 \\
N of Valid Cases & 431.00 & & \\
\hline
\end{tabular}

The $\mathrm{p}$-value $=0.00$ is less than 0.05 , therefore the null hypothesis is rejected while the alternative is accepted which states there is significant relationship between performance of knee and pain

Table 12: Influence of knee pain on psychosocial life and sleep disturbances

Because of my joint problems, I am not able to go out and as a result I feel lonely*

What level of knee pain have you experienced during bending knee fully?

\begin{tabular}{|c|c|c|c|c|c|c|}
\hline \multirow{8}{*}{$\begin{array}{l}\text { I am not able } \\
\text { to go out } \\
\text { and as a } \\
\text { result I feel } \\
\text { lonely }\end{array}$} & & No Pain (1) & Mild Pain (2-4) & Moderate Pain (5-7) & $\begin{array}{c}\text { Worst Pain } \\
\text { (10) }\end{array}$ & Total \\
\hline & Never & 0 & 0 & 1 & 0 & 1 \\
\hline & Rarely & 12 & 35 & 112 & 0 & 159 \\
\hline & Sometimes & 3 & 29 & 36 & 0 & 68 \\
\hline & Often & 1 & 37 & 121 & 3 & 162 \\
\hline & Always & 1 & 8 & 14 & 0 & 23 \\
\hline & & 0 & 3 & 12 & 3 & 18 \\
\hline & Total & 17 & 112 & 296 & 6 & 431 \\
\hline
\end{tabular}

Table 13: $\chi^{2}$ Test of effect of knee pain on psychosocial life and sleep disturbances

\begin{tabular}{lccc}
\hline & Value & df & Asymp. Sig. (2-sided) \\
\hline Pearson Chi-Square & $58.611^{\mathrm{a}}$ & 15 & 0.00 \\
Likelihood Ratio & 42.817 & 15 & 0.00 \\
No of Valid Cases & 431 & & \\
\hline
\end{tabular}

The p-value $=0.00$ is less than 0.05 , therefore the null hypothesis is rejected while the alternative is accepted which states there is significant influence of knee pain on psychosocial life and sleep disturbances 
A PRELIMINARY INVESTIGATION OF THE BIOMETRY OF KNEE PAin FOR DEVELOPMENT OF THERAPEUTIC ... 0. 0. E. Ajibola, et. al

Table 14: Influence of knee pain on functionality

\begin{tabular}{l|lcccccc}
\hline \multicolumn{7}{c}{ What level of knee pain have you experienced during kneeling? } \\
\hline \multirow{2}{*}{$\begin{array}{l}\text { Does your } \\
\text { knee stiffen }\end{array}$} & \multicolumn{7}{c}{ Mild } \\
when & & No Pain & Pain & Moderate Pain & Severe Pain & Worst Pain & Total \\
moving? & $(1)$ & $(2-4)$ & $(5-7)$ & $(8-9)$ & $(10)$ & \\
\cline { 2 - 8 } & Never & 6 & 13 & 25 & 6 & 0 & 50 \\
& Rarely & 4 & 30 & 72 & 5 & 2 & 113 \\
& Sometimes & 2 & 52 & 160 & 18 & 9 & 241 \\
& Often & 0 & 5 & 13 & 2 & 1 & 21 \\
& Always & 0 & 2 & 3 & 1 & 0 & 6 \\
\hline Total & 12 & 102 & 273 & 32 & 12 & 431 \\
\hline
\end{tabular}

Table 15: Chi-Square Tests

\begin{tabular}{lccc}
\hline & Value & $\mathrm{df}$ & Asymp. Sig. (2-sided) \\
\hline Pearson Chi-Square & $29.320^{\mathrm{a}}$ & 16 & 0.022 \\
Likelihood Ratio & 25.786 & 16 & 0.057 \\
$\mathrm{~N}$ of Valid Cases & 431 & & \\
\hline
\end{tabular}

The p-value $=0.022$ is less than 0.05 , therefore the null hypothesis is rejected while the alternative is accepted which states there is significant influence of knee pain on functionality.

Of primary interest in this work is the statistical analysis of various parameters of pain in an OA patient with the intent to provide a platform for therapeutic treatment of major presentations of OA. Hitherto, drug application is the preferred method of managing the ailment but the side effects of drug administration in OA cannot be overemphasized [20]. Natural supplements and extracts from edible crops have proven to be effective in the treatment of the conditions associated with $\mathrm{OA}$ their adverse effects have proven to be grave indeed [21]. According to literature, OA inflict worse pain moves the affected joint thus imposing restriction on the patient's economic activities [22]. The pain may be worse after a particular pattern of movement, such as climbing up or descending the stairs. Pain varies depending on how active someone engages in an exercise. Knee OA is a major challenge to the society [2]. Its symptoms can affect one or both knees. Many factors can increase its risk, and it's often a combination of the aforementioned factors that leads to the condition.

Almost anyone is prone to osteoarthritis, but the incidence increases as the individuals ages from 40yrs, becomes overweight, of a female gender, or with a previous knee injury. There's a great deal of evidence that being overweight increases the strain on the joints, especially the knees. There are lots of measures engaged by respondents in managing the knee OA but the most common measure in this study is the use of painkiller. There is no cure for arthritis but there are a number of treatments that may help relieve the pain and relief of swollen knee without any adverse effect. The goals of osteoarthritis treatment include alleviation of pain and improvement of functional status. Management depends upon the identification of risk factors and the intensity of pain. All drugs come with side effects. Many are minor, some come by way of inconveniences, a few are serious, and some are catastrophic. A therapeutic device (thermotherapy) can be developed to manage pain in kneel osteoarthritis.

\section{CONCLUSION}

In this study, we have carried out a biometric analysis of kneel osteoarthritis with respect to its symptomatic pain. One of the main objectives of this study is to promote a better understanding of the pathomechanisms of pain presentation associated with the degenerating trend in osteoarthritis. This study established strong positive relationship between knee pain and poor functionality, psychosocial life and sleep disturbance on one hand and positive correlation between overweight, ageing, high level of stressful activities on the other hand. However, there seem to be no barrier between knee osteoarthritis and employment as the disparity between the incidences of the ailment as regards both the employed and the unemployed is insignificant. This study is useful for the development of a therapeutic device for the management of the pain presentation in osteoarthritis and related disease. 


\section{REFERENCES}

[1] Felson, D.T. Osteoarthritis: Harrison's Principles of Internal Medicine, Chapter 332. McGraw-Hill Medical. 2015.

[2] Woolf, A.D., Pfleger, B. Burden of major musculoskeletal conditions. Bulletin of the World Health Org. 81:646 - 656. 2003.

[3] OARSI. Osteoarthritis: A Serious Disease, Submitted to the U.S. Food and Drug Administration. OARSI White Paper: OA a Serious Disease_121416_1. Osteoarthritis Research Society International, USA. 2016.

[4] "Osteoarthritis - Overview and Treatment Options - Plant Based Pharmacist." http://www.plantbasedpharmacist.com/osteoarth ritis-treatment-options/ [Accessed: 06-December2017].

[5] Last, W. Arthritis and rheumatism (A Holistic Therapy). $\quad$ http://www.health-sciencespirit.com/arthritis.html. [Accessed: 06December-2017].

[6] Kareem, 0.0. Biometry of knee osteoarthritis as a pedestal for the construction of a therapeutic device for the control of osteoarthritis. M.Sc. Thesis. University of Lagos, Lagos, Nigeria. 2017.

[7] M. Garrett Hyman. Knee Osteoarthritis Diagnosis Arthritis-Health." $\quad$ https://www.arthritishealth.com/types/osteoarthritis/kneeosteoarthritis-diagnosis. [Accessed: 29-October2017]. 2011.

[8] M. Brian Wu, M.B., Morrison, W. Stages of Osteoarthritis of the Knee. https://www. medicalnewstoday.com/kc/stages-osteoarthritisknee-310579. [Accessed: 06-December-2017]. 2016.

[9] The Directorate: Affordable Medicines. Standard treatment guidelines and essential medicines list for South Africa. The National Department of Health, Pretoria, South Africa. 2012.

[10] Ajibola, 0.0.E. and Folorunso, O.P. Analysis, design and construction of electronics ice cuff for athletes. International Journal of Medical Engineering and Informatics. 9:220-236. 2017.

[11] J. Dawson, R. Fitzpatrick, J. Fletcher, and R. Wilson, "Osteoarthritis Affecting the Hip and Knee." https://www.birmingham.ac.uk/ [Accessed: 28October-2017].

[12] Centers for Diseases control and prevention (CDC 24/7: Saving lives and protecting people)
"Osteoarthritis Basics Arthritis CDC." https://www.cdc.gov/arthritis/basics/osteoarthrit is.htm. [Accessed: 27-October-2017].

[13] M. Brandon J. Kambach. Applying Heat vs. Cold to an Arthritic Joint. https://www.arthritishealth.com/treatment/alternativetreatments/applying-heat-vs-cold-arthritic-joint. [Accessed: 07-Dec-2017]. 2015.

[14] Benzon, H., Rathmell, J., Wu, C., Turk, D. and Argoff, C. (editors). Raj's Practical Management of Pain, Elsevier, Philadelphia, USA. pp. 1319. 2013.

[15] Kosuwon W, Sirichatiwapee W, Wisanuyotin T, Jeeravipoolvarn P, Laupattarakasem W. Efficacy of symptomatic control of knee osteoarthritis with $0.0125 \%$ of capsaicin versus placebo. Journal of Medical Association of Thailand. 93:1188-95. 2010.

[16] Nadler, S.F, Weingand, K., Kruse, R.J. The Physiologic Basis and Clinical Applications of Cryotherapy and Thermotherapy for the Pain Practitioner. Pain Physician, 7:395-399. 2004.

[17] Ajibola, O.O.E, Fagbolagun, K.O., Folorunso, O.P. Design and Fabrication of a Moist Heat Therapy Device for Treating Non-specific Low Back Pain. West Indian Journal of Engineering (in press), 2018.

[18] Starkey C. Therapeutic modalities. F.A Davis Company, Philadelphia, USA. 2004.

[19] Stephen J.M., Argus C., Driller M.W. The relationship between body composition and Thermal responses to Hot and Cold water immersion. J. Human perform. Extreme Environ. II; 2:1. 2014.

[20] Arthritis Research UK. Complementary and alternative medicines for the treatment of rheumatoid arthritis, osteoarthritis and fibromyalgia.

http://www.arthritisresearchuk.org/ [Accessed: 27-October-2017].

[21] Mur E, Hartig F, Eibl G, Schirmer M. Randomised double-blind trial of an extract from the pentacyclic alkaloid-chemotype of Uncaria tomentosa for the treatment of rheumatoid arthritis. J. Rheum. 29:678-81. 2002.

[22] Susanne Bruyère, Sophie Mitra, Sara VanLooy, Tom Shakespeare, Ilene Zeitzer. Work and employment. World report on disability. World Health Organisation. 233-252. 2011. 